\title{
Descripción anatómica e histológica del tracto digestivo de Nicuro Pimelodus blochii (Valenciennes, 1840)
}

\author{
An anatomical and histological description of the digestive tract \\ of Bloch's catfish Pimelodus blochii (Valenciennes, 1840)
}

\author{
Descrição Anatômica e histológica do trato digestório de Nicuro \\ Pimelodus blochii (Valenciennes, 1840)
}

\author{
Leslie Guzmán Beltran ${ }^{1}$, Diana Santana V', Helicenda Verdugo $M^{2}$, Edwin Gómez-Ramirez ${ }^{3 *}$, \\ Hernán Hurtado Giraldo *
}

\footnotetext{
MV, Esp. Laboratorio de Embriología, Facultad de Ciencias Básicas, Universidad Militar Nueva Granada. Cajicá Colombia.

2 Biologa, Laboratorio de Embriología Facultad de Ciencias Básicas, Universidad Militar Nueva Granada.

3 Biologo, MSC, ${ }^{4}$ Biologo, PhD,

* Grupo de Ictiología, Programa de Biología Aplicada, Facultad de Ciencias Básicas, Universidad Militar Nueva Granada. Campus Cajicá

Email: Edwin.gomez@unimilitar.edu.co
}

Recibido: agosto 24 de $2012 \quad$ Aceptado: mayo 14 de 2013

\begin{abstract}
Resumen
P. blochii es una especie de consumo de gran importancia en las cuencas del Magdalena y la Orinoquía, sin embargo, aún se desconocen aspectos básicos de su biología. Por ello, se realizó una descripción anatómica e histológica del tracto digestivo y glándulas anexas. Siete individuos fueron sacrificados y procesados para histología en parafina. Se realizaron cortes semiseriados de $7 \mu \mathrm{m}$ que se tiñeron con H\&E. Anatómicamente esta especie no presenta lengua, el esófago es corto y muscular, el estómago relativamente grande y muscular. El intestino tiene una longitud intermedia, poco musculoso. Hígado no lobulado y el páncreas es difuso. Histológicamente $P$. blochii presentó una organización tisular similar a otros teleósteos, compuesto de cuatro capas: mucosa, submucosa, muscular y serosa. La mucosa del esófago es un epitelio plano estratificado con gran número de células caliciformes, la submucosa tejido conectivo laxo (similar para estómago e intestino), la capa muscular es estriada con dos orientaciones de músculo (longitudinal interna y una circular externa). La mucosa del estómago está compuesta de epitelio cilíndrico simple; presentando abundantes glándulas gástricas tubulares en la región cárdiaca y fúndica, con disminución de estas en la región pilórica. El intestino presenta similar epitelio al del esófago, con aumento de células caliciformes y presencia de vellosidades. La capa muscular del estómago y del intestino está formada por dos capas de músculo liso (interna circular y una externa longitudinal). El hígado presentó hepatocitos con núcleos prominentes, generalmente centrados y dispuestos en forma de cordones. El páncreas presento dos organizaciones tisulares; la exocrina con células acinares y la endocrina con islotes de Langerhans. Una boca relativamente grande, esófago corto, un estomagó grande musculoso con gran número de glándulas gástricas, y un intestino de longitud intermedia (coeficiente intestinal 0.93), indicaría que P. blochii es un pez de hábitos omnívoros con tendencia a carnívora.
\end{abstract}

Palabras clave: Silúridos, bagres, hábito alimenticio, biología básica, glándulas anexas. 


\begin{abstract}
P. blochii from the Magdalena and the Orinoquía basins is a very important for human consumption. However, most of its basic biology is unknown. For this reason an anatomical and histological description of its digestive tract an accesory glands was made. Seven individuals were sacrificed and processed for paraffin histology. Semiserial sections were obtained and stained with H\&E. Anatomically, this species has no tongue, oesophagus is short and muscular, stomach is relatively large and muscular. The intestine has an intermediate length, with scarce muscle. The liver did not show any lobes and the pancreas is diffuse. Histologically, P. blochii did presents a tissular organization similar to other teleosts, having four layers: mucosae, submucosae, muscular and serous. Oesophagus mucosae is made by squamous stratified epithelium with a large number of globet cells, submucosae (similar for stomach and intestine) does exhibit a loose connective tissue, muscular layer presents internal longitudinal and external circular striated muscle. Stomach mucosae has simple cilindrical epithelium, with many tubular gastric glands in the cardiac and fundic areas, and few of these glands in the piloric area. The intestine epithelium is similar to the oesaphagus epithelium, but with more globet cells and with folds. Stomach and intestine muscular layers are made by external smooth muscle layer and a internal smooth muscle layer. Liver does present row arranged hepatocytes with large and generally centered nuclei. In pancreas two different tissular arrangements were present: exocrine with acinary cells, and endocrine with Langerhans islets. A relatively large mouth, a short oesophagus, a large muscular stomach with many gastric glands, and an intermediate length intestine (intestinal coefficient 0.93), would indicate that P. blochii in an ommivorous fish with a carnivorous tendency.
\end{abstract}

Key words: Silurids, catfishes, feeding habits, basic biology, accessory glands.

\begin{abstract}
Resumo
P. Blochii é uma especie de consumo de grande importancia da bacia do rio Magdalena e da bacia da Orinoquia, embora não se conhecen aspectos essenciaes da seu biologia. Por isso, no presente trabalho objetivou-se se realizar uma descrição anatómica e histologica do trato digestivo e das glândulas anexas. Sete indivíduos de P. Blochii foram abatidos e processados para inclusão em parafina. Foram realizados cortes semiseriados com uma espessura de $7 \mu \mathrm{m}$ e corados com H\&E. Anatomicamente esta espécie não apresentou língua, o esôfago é curto e muscular, o estômago é relativamente grande e muscular. O tubo digestório tem uma longitude intermedia, pouco muscular. O fígado não é lobulado e o pâncreas é difuso. Histologicamente o P. Blochii apresenta o padrão geral dos teleósteos, é composto por quatro camadas: a mucosa, submucosa, muscular e serosa. No esôfago, o epitelio da mucosa é plano estratificado, com grande numero de células caliciformes, a submucosa é de tecido conetivo laxo (similar à do estomago e intestino), a camada muscular é estriada com duas organizações de músculo (longitudinal interna e circular externa). A mucosa do estômago é composta pelo epitélio cilíndrico simples, apresentando bastantes glândulas tubulares na região cardíaca e fundo proximal. Tem disminuição da região pilórica. No Intestino, se evidenciou igual tipo epitelial do que o esôfago com aumento de células caliciformes e presença de vilosidades. A camada muscular do estômago e intestino é formada por duas camadas de musculo liso (circular interna e longitudinal externa). No fígado observou-se hepatócitos com núcleo proeminente, geralmente focados e preparados na forma de cordões; o pâncreas apresentou duas organizações tissulares na porção exócrina com células acinares e a endócrina com ilhotas de langernhans. Uma boca relativamente grande, o esôfago curto, um estomago grande e musculoso com bastantes glândulas gástricas, e um tubo digestório de longitude intermedia (quociente intestinal 0.93), os dados indicam que o P. blochii é um peixe que apresenta comportamento omnívoro com tendências carnívoras.
\end{abstract}

Palavras chave: Silúridos, bagres, hábito alimentar, básica biologia, glândulas anexas.

\section{Introducción}

En Colombia de las 173 especies de peces que son aprovechadas y utilizadas para el consumo, los Siluriformes representan el 36\%, tienen amplia aceptación comercial en el país y por su abundancia son económicamente representativos (Lasso et al., 2010); además son apetecidas por su excelente calidad de carne, su uso en la pesca deportiva y ornamental en su etapa juvenil (Padilla et al., 2001). Sin embargo, el conocimiento que se tiene de los aspectos básicos de su biología en la mayoría de los casos es incompleto generando en ocasiones equívocos cuando se trata de desarrollar tecnologías de cultivo. Algunas tecno- logías incluyen la elaboración de concentrados para cada especie, que suelen ser deficientes e insostenibles económicamente; si se tiene en cuenta que no se consideran las diferencias en el sistema digestivo de tipo anatómico, histológico y fisiológico (Eslava et al., 2001). Esto ocurre con el Silúrido Pimedolus blochii, el cual se distribuye en las cuencas del Golfo de Paria (Brasil), río Amazonas, Essequibo, Tocantis, Orinoco, Magdalena, Cauca, Sinú, San Jorge, Cesar, Atrato y Baudó (Maldonado et al., 2005). P. blochii se caracteriza por tener una boca subterminal con dientes premaxilares cónicos, pequeños y delgados; cabeza cubierta por una delgada piel, el techo del cráneo esta 
ornamentado con poros sensoriales y estriaciones suaves pero visibles, la aleta adiposa es corta, se inserta en el último tercio de la longitud estándar, con su margen triangular (Villa-Navarro, 2010). Se conocen sus hábitos alimenticios en vida silvestre donde se comporta como omnívoro oportunista, con un amplio rango de especies que incluyen insectos acuáticos y terrestres, crustáceos, peces, macrófitas y varios tipos de semillas de gramíneas y leguminosas. En cuanto a su reproducción presentan una estrategia reproductiva estacional, con un único desove en el año (López y Casas-Jiménez, 2007).

Aunque hay pocos trabajos del tracto digestivo de especies nativas, estos han venido en aumento como es el caso de: Piaractus brachypomus (Eslava et al., 2000; Muñoz et al., 2006), Pseudoplatystoma corruscans (Seixas-Filho et al., 2001), Brycon siebenthalae (Eslava et al., 2001), Pimelodus pictus (Olaya et al., 2007), Pimelodus maculatus (Santos et al., 2007), Rhamdia quelen (Hernández et al., 2009), Ariopsis seemanni (Gómez et al., 2010). El objetivo del trabajo fue describir anatómica e histológicamente el tracto digestivo y algunas glándulas anexas de adultosde $P$. blochii con el fin de aumentar el conocimiento de la biología básica, lo cual puede ser útil al momento de incorporar esta especie en programas de acuicultura y el diseño de dietas artificiales.

\section{Materiales y métodos}

Se trabajó con siete individuos adultos de P. blochii capturados en el río Meta entre Enero y Febrero del 2003, en el Municipio de Cabuyaro (Meta, Colombia) con una longitud total promedio de $25.46 \mathrm{~cm} \pm 3.32$ y un peso promedio de $149.4 \mathrm{~g} \pm 52.1$, los cuales fueron mantenidos en estanques de tierra en la Estación Piscícola La Terraza, ubicada en la ciudad de Villavicencio. Fueron anestesiados con una sobredosis de benzocaina $(0,1 \mathrm{~g} / \mathrm{L})$ y sacrificados por sección medular al nivel de la espina supraoccipital, teniendo en cuenta las guías para el manejo ético de peces para la investigación (AVMA, 2007).

En la necropsia se disectaron ventralmente para identificar y describir la orientación, apariencia, disposición del esófago, estómago, intestino, hígado y páncreas. También se calculó el coeficiente intestinal $(\mathrm{Cl})$ donde $\mathrm{Cl}=\mathrm{L}_{\mathrm{i}} \cdot \mathrm{L}_{\mathrm{s}}{ }^{-1}$ donde $\mathrm{L}_{\mathrm{i}}$ es la longitud intestinal $(\mathrm{cm})$ y $\mathrm{L}_{\mathrm{s}}$ es longitud estándar (cm) (Albrecht et al., 2001). Los órganos fueron extraídos y fijados en para formaldehído al $4 \%$, ( $\mathrm{pH}$ 7.2-7.3), durante cinco días a $4^{\circ} \mathrm{C}$. Las muestras fueron procesadas histológicamente en el laboratorio de Embriología de la Universidad Militar Nueva Granada. Las estructuras fueron sometidas a un proceso de deshidratación en concentraciones crecientes de etanol y se incluyeron en parafina (MERCK, punto de fusión $52-54{ }^{\circ} \mathrm{C}$ ) (Agarwal, 1996). Se realizaron cortes transversales semiseriados de $7 \mu \mathrm{m}$ de espesor en un micrótomo rotatorio (CUT SLEE 4060) y los cortes se tiñeron con la técnica H\&E de Mayer y Harris. Para el estudio histológico se tuvo en cuenta la presencia de las diferentes capas del sistema digestivo; mucosa, submucosa, muscular y serosa, así como también las glándulas hígado y páncreas (Olaya et al., 2007).

\section{Resultados}

\section{Anatomía del tracto digestivo de P. blochii}

Los ejemplares de $P$. blochii presentan una boca subterminal con una cavidad amplia. Presencia de numerosos dientes de tipo viliformes dispuestos en dos bandas sobre los maxilares, ausencia de lengua. A cada lado de la región de la faringe se encuentran ubicados cuatro arcos branquiales; en sus bordes internos se encuentran pocas branquiespinas, fuertes y espaciadas entre sí. En los bordes externos se pueden observar los filamentos branquiales los cuales son largos y numerosos.

El esófago es un tubo corto y muscular con una longitud de 0,81 $\pm 2,6 \mathrm{~cm}$, se extiende desde la zona branquial hasta la entrada del estómago, la parte posterior se halla en contacto con la vejiga natatoria. El estómago en forma de " $U$ ", es grande y musculoso, su longitud es de 1,81 $\pm 0,36 \mathrm{~cm}$, identificándose tres regiones: cárdica, fúndica y pilórica. La cárdica inicia en la unión entre el esófago y el estómago, la región fúndica o región del fondo, en forma de saco ciego, y la región pilórica es la parte más próxima al intestino con una disminución notable de su diámetro.

El intestino es un tubo largo que inicia en el esfínter pilórico del estómago y termina en el ano; con una longitud de 15, $4 \pm 2,2 \mathrm{~cm}$, se inicia en la parte media izquierda del estómago rodeándolo anteriormente,presenta cinco curvas en la parte media de la cavidad abdominal conocidas como asas intestinales, continua por la región media ventral para terminar en el ano. El coeficiente intestinal para $P$. blochii fue de $0.93 \pm 0.07$ (Tabla 1). El hígado es de color rojo, situado en la parte anterior de la cavidad visceral, en la parte craneal del estómago. El páncreas es difuso y de color blanquecino, se halla distribuido sobre cuatro órganos: estómago, intestino, hígado y vesícula biliar. 
Tabla 1. Registro de longitudes $P$. blochii: longitud estándar, esófago, estómago, intestino y coeficiente intestinal. Cada valor representa el promedio de la longitud en $\mathrm{cm}+/$ - la desviación estándar. El coeficiente intestinal representa un valor absoluto.

\begin{tabular}{|l|c|}
\hline \multicolumn{1}{|c|}{ Parámetro } & Promedio \\
\hline Longitudestándar & $19.34+/-2.64$ \\
\hline Longitud del esófago & $0.81+/-0.17$ \\
\hline Longitud del estómago & $1.81+/-0.41$ \\
\hline Longitud del intestino & $15.42+/-2.22$ \\
\hline Longitud total del tracto digestivo & $18.34+/-3.15$ \\
\hline Coeficiente intestinal & $0.93+/-0.07$ \\
\hline
\end{tabular}

\section{Histología del tracto digestivo de P. blochii}

El tracto digestivo de esta especie presenta cuatro capas constitutivas: mucosa, submucosa, muscular y serosa, variando de espesor a lo largo del tubo digestivo (Figura 1).

Esófago. El epitelio de la mucosa es plano estratificado, presenta un gran número de células caliciformes, criptas prominentes y depresiones profundas. La submucosa se compone de tejido conectivo laxo que soporta la mucosa (Figura 2). La capa muscular es estriada, con dos organizaciones del músculo una longitudinal interna y una circular externa de mayor espesor que la primera (Figura3). En la capa serosa se observó tejido conectivo laxo y algunos vasos sanguíneos.
Estómago. La mucosa del estómago está compuesta por epitelio cilíndrico simple; se divide en dos regiones histológicamente diferenciables: la primera incluye a la región cárdica y fúndica que presenta abundantes glándulas gástricas tubulares (Figura 4); y la región pilórica en donde se encuentran en menor proporción. La submucosa está compuesta por tejido conectivo laxo. La capa muscular está formada por dos capas de músculo liso con dos orientaciones, una interna circular y una externa longitudinal, las dos capas son de considerable espesor. La serosa es delgada y se observa tejido conectivo laxo.

Intestino. La mucosa presenta un epitelio cilíndrico simple con abundantes células caliciformes, el epitelio del intestino se observa plegado con criptas prominentes y presencia de vellosidades. La submucosa está constituida por tejido conectivo laxo, la capa muscular es de menor espesor que en el estómago formada por músculo liso en dos organizaciones, una organización circular interna de mayor espesor en comparación con la capa siguiente, la cual presenta una organización longitudinal externa (Figura 5).

Glándulas anexas. El hígado de P. blochii no presenta lobulación, y está asociado con el páncreas exocrino. Los ductos biliares se caracterizan por presentar epitelio cúbico simple y abundante tejido conectivo. Los hepatocitos exhiben núcleos prominentes (Figura 6) y el citoplasma es basófilo delimitados por sinusoides encargados de irrigar el tejido.

En el páncreas la porción exocrina está dentro de una cápsula de tejido conectivo laxo muy delgada, se pue-

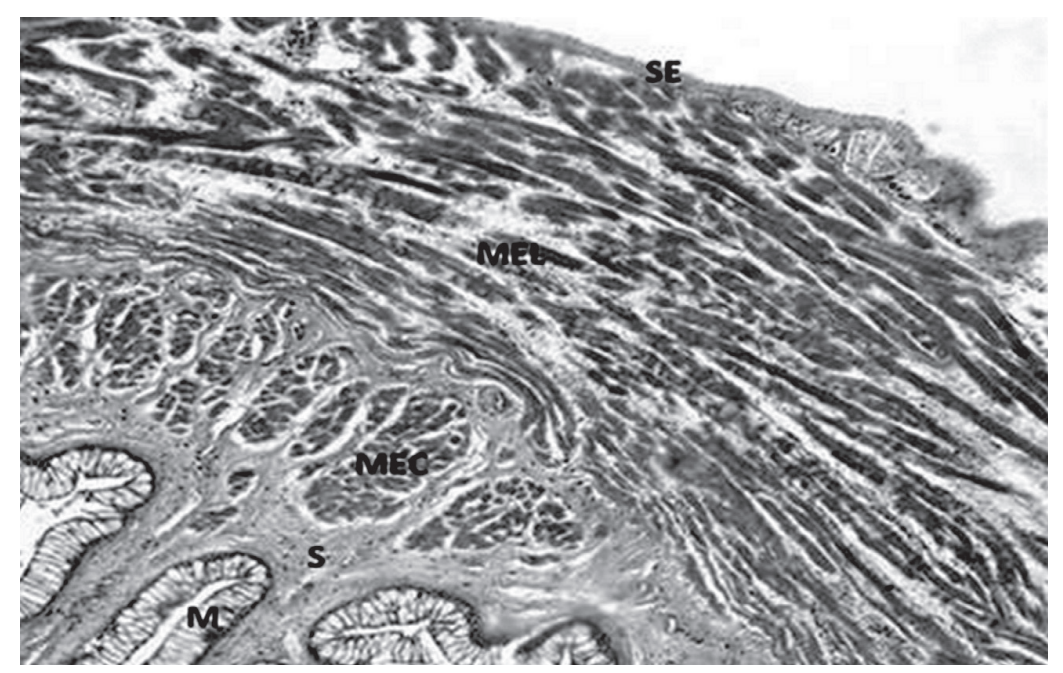

Figura 1. Esófago de $P$. blochii. Panorámica de las capas constitutivas del tracto digestivo. Mucosa (M), submucosa (S), músculo estriado circular (MEC), músculo estriado longitudinal (MEL) y serosa (SE), 130X. H\&E. 


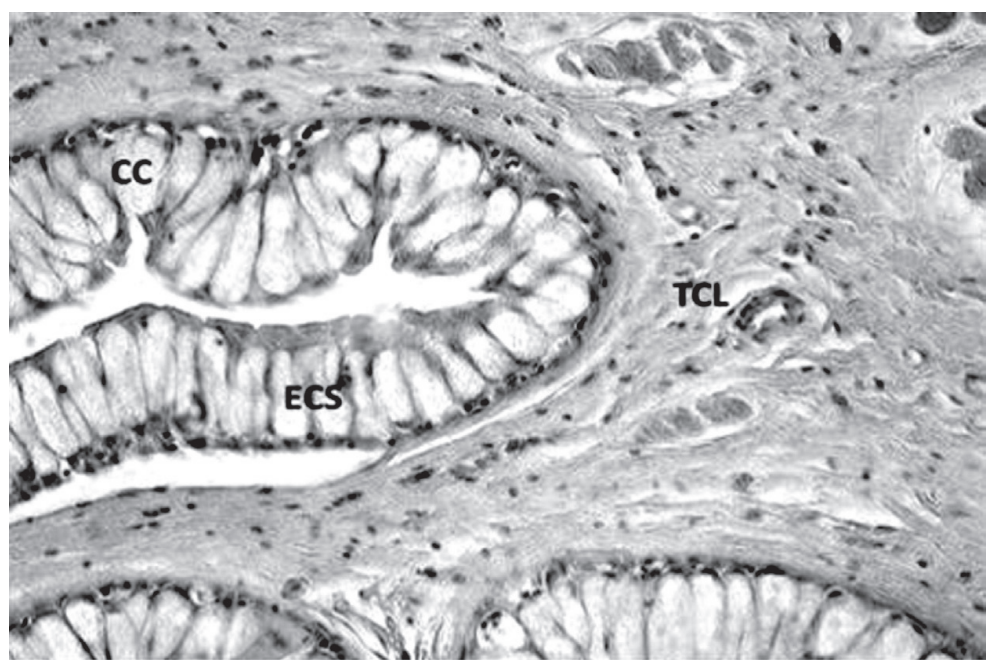

Figura 2. Detalle de la mucosa del esófago de P. blochii. Se observa epitelio plano estratificado (ECS) con abundantes células caliciformes (CC) y submucosa de tejido conectivo laxo (TCL), 400X. H\&E.

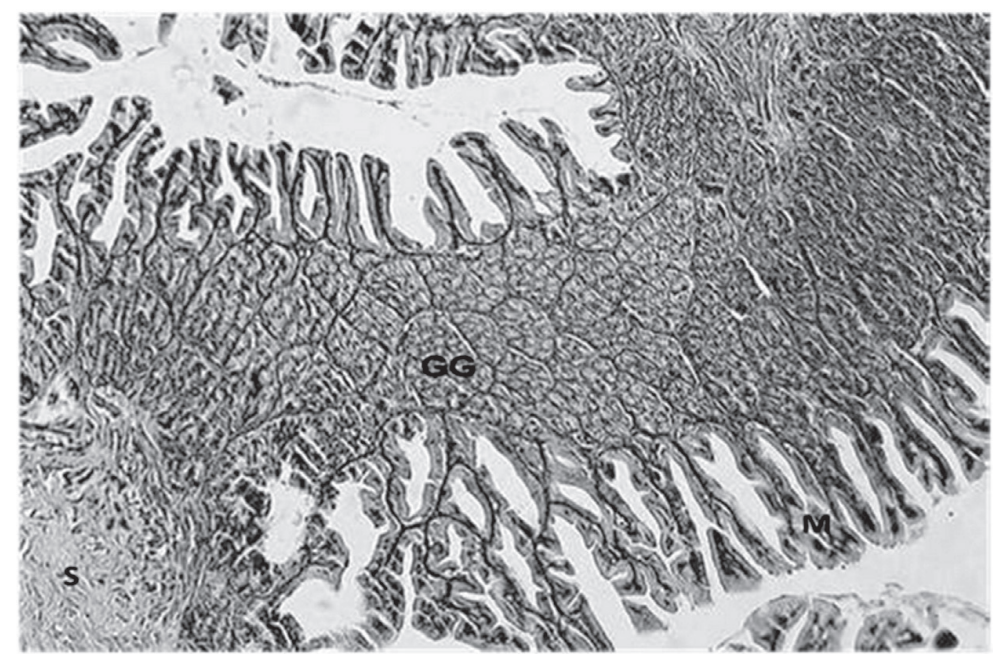

Figura 3. Panorámica de la región fúndica del estómago de $P$. blochii. Se observa la mucosa $(\mathrm{M})$ compuesta por epitelio cilíndrico simple con glándulas gástricas tubulares (GG) y parte de submucosa compuesta por tejido conectivo laxo (S), 130X. H\&E.

den observar células acinares que poseen un núcleo basal definido y un citoplasma apical con gránulos de cimógeno, presentan una organización irregular. La porción endocrina se halla conformada por Islotes de Langerhans (Figura 6), separados por fibras de tejido conectivo laxo de la mucosa correspondiente a la porción exocrina.

\section{Discusión}

La boca y cavidad bucal de $P$. blochii son relativamente grandes en proporción de su tamaño corporal y presenta gran número de dientes viliformes, lo que indica que esta especie puede tragar presas enteras y los dientes les permiten raspar el fondo en busca de alimento, aunque por este modo de alimentación es posible que también ingieran detritos al momento de forrajear (Vásquez-Torres, 2004; Gómez et al., 2010). Esto coincide con los estudios de contenido estomacal reportados por López-Casas y Jiménez (2007) donde fue común encontrar material vegetal representado por pelos absorbentes del sistema radicular de macrófitas y semillas. La morfología bucal es similar a la presentada por otros Silúridos como: Pseudoplatystoma fasciatum (Padilla et al., 2001), Pimelodus pictus (Olaya et al., 2007); Ariopsis seemanni (Gómez et al., 2010). El 


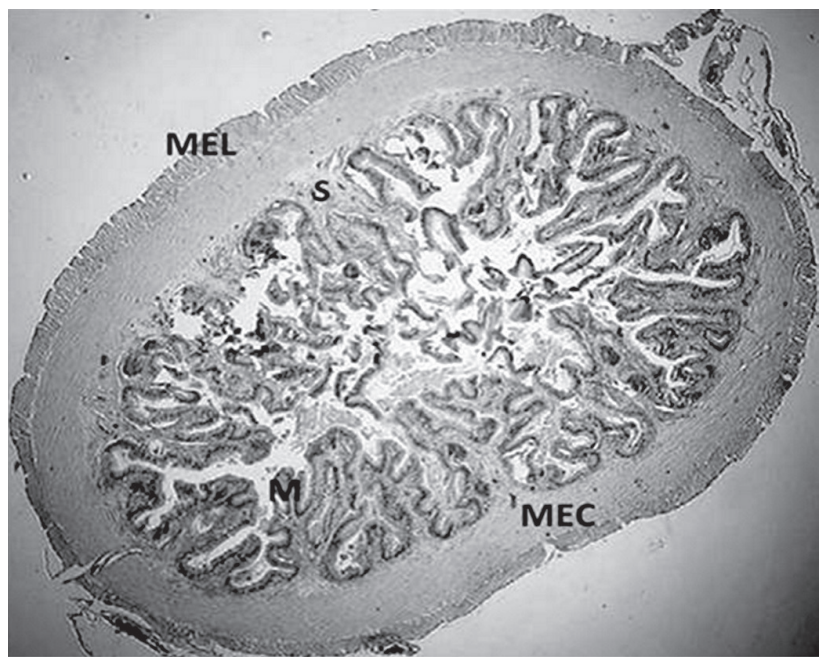

Figura 4. Panorámica del intestino de $P$. blochii. Se observan tres capas de organización del tracto digestivo: Mucosa de epitelio cilíndrico simple (M), submucosa de tejido conectivo laxo (S), músculo estriado circular interno (MEC) y músculo estriado longitudinal externo (MEL). 25X. H\&E.

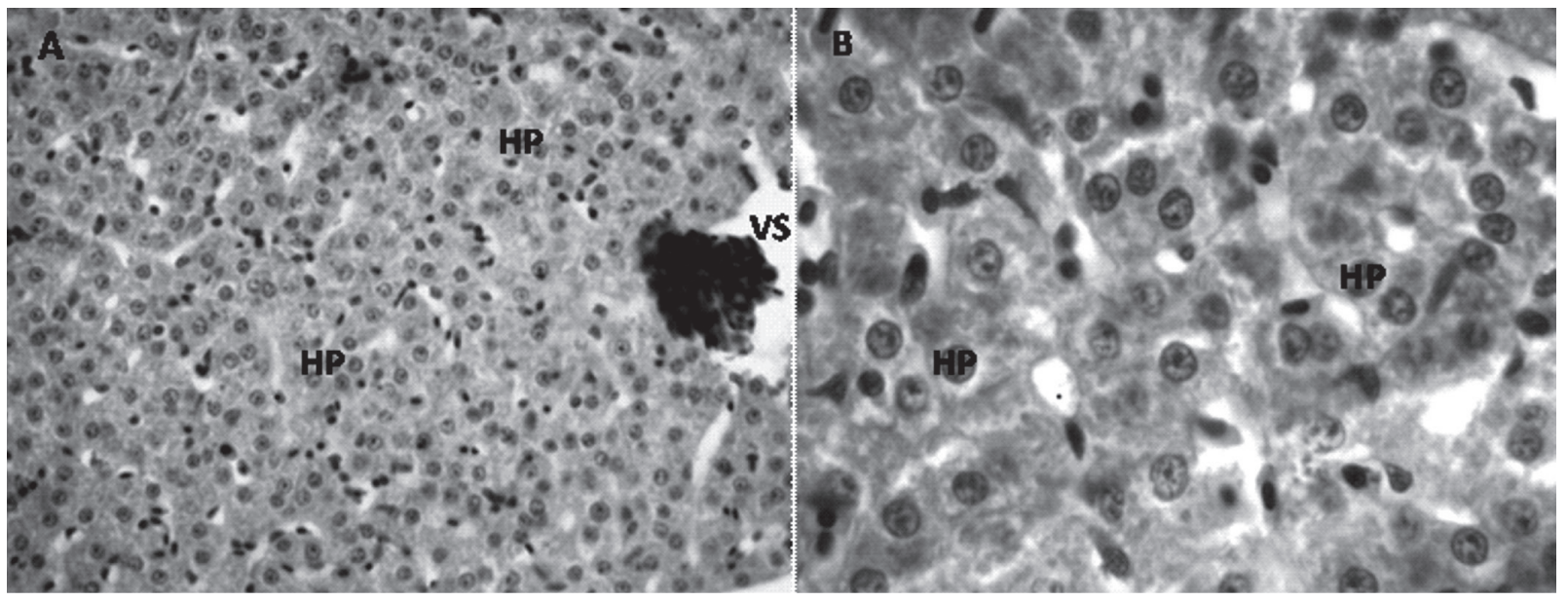

Figura 5.(A). Panorámica del hígado de P. blochii. Se observa hepatocitos (HP) agrupados en cordones y vasos sanguíneos (VS), 400X. H\&E. (B). Detalle del hígado, hepatocitos (HP). 1000X. H\&E.

bajo número de branquiespinas y el espacio entre las mismas indica una baja capacidad filtradora en esta especie, lo cual es característico de especies carnívoras y algunas omnívoras (Vásquez- Torres, 2004). El estómago de $P$. blochii es un saco muscular relativamente grande entre el esófago y el intestino con pliegues anchos y profundos, características que comparte con otros Silúridos (Olaya et al., 2007; Hernández et al., 2009; Gómez et al., 2010): Lo anterior le permite una alta capacidad de distensión, para alojar presas de gran tamaño, lo cual es característico de peces con hábitos alimenticios carnívoros (Vásquez-Torres, 2004). Un estómago musculosos permite a su vez movimien- tos peristálticos fuertes lo que ayuda en la mezcla del alimento con los productos de secreción de las glándulas gástricas (Day et al., 2011). La longitud del intestino así como el contenido estomacal están directamente relacionados con los hábitos alimenticios de la especie, P. blochii presentó una coeficiente intestinal de 0.93, que generalmente presentan especies carnívoras (0.7-0.9) (Albrecht et al., 2001; Vásquez-Torres, 2004). Sin embargo, Day y colaboradores (2011) manifiestan, que no solo la longitud intestinal en función de la longitud corporal es un criterio para determinar el habito alimenticio, un ejemplo de esto lo proveen algunas especies de peces del orden Beloniformes, pues presen- 


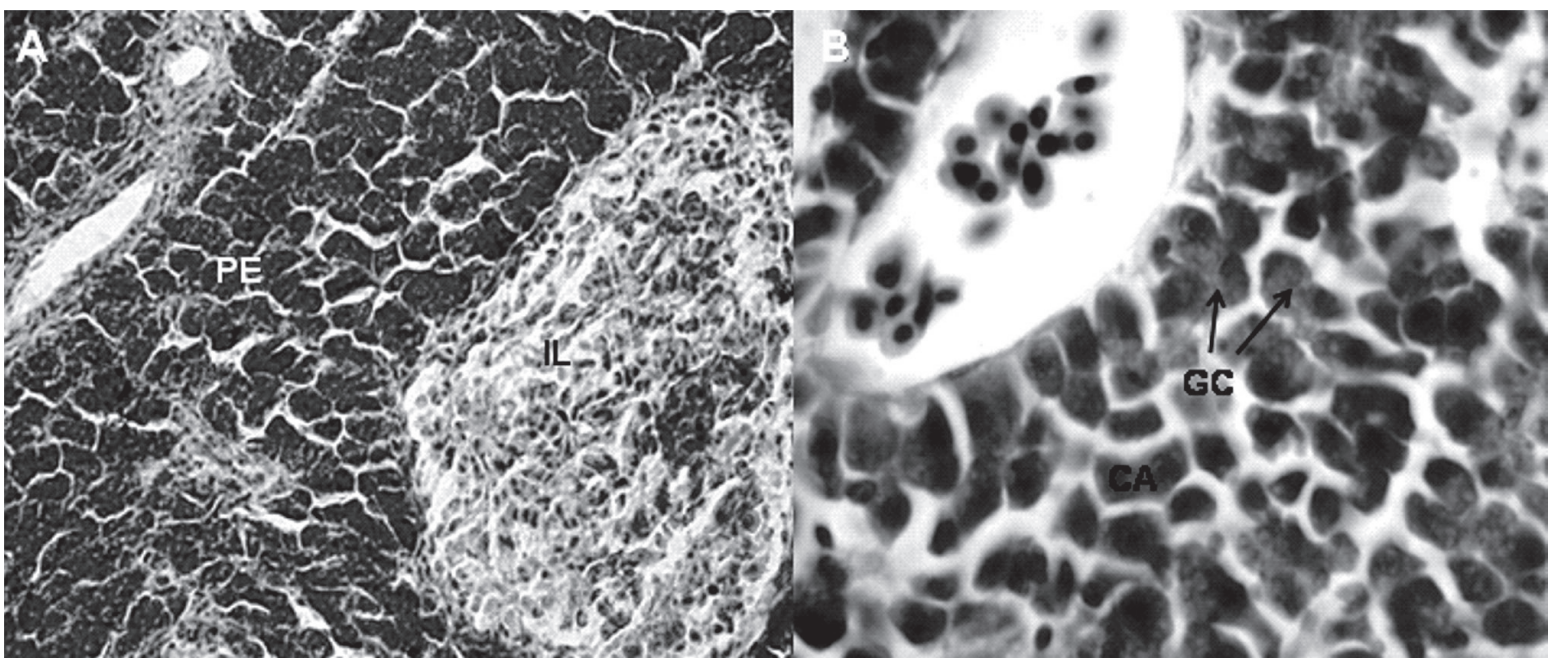

Figura 6. Panorámica de páncreasde P. blochii. (A) Se observa porción exocrina (PE) y parte endocrina caracterizada por Islotes de Langerhans (IL). 400X H\&E. (B) Detalle de región exocrina. (CA) células acinares y gránulos de cimógeno (GC) 1000X.H\&E.

tan tractos digestivos cortos y algunos hasta carecen de estómago, pero aun así poseen diferentes hábitos alimenticios (herbívoros, planctívoros y carnívoros).

El intestino de P. blochii es un tubo corto con cinco asas en comparación con el omnívoro Brycon orbygnianus que presenta nueve asas intestinales (Seixas Filho et al., 2000), sin embargo, comparado con el carnívoro Salminus affinis es más largo (García et al., 2008). Considerando que las asas intestinales permiten el transporte lento del material en procesamiento, ayudando a retardar el paso del alimento y aumentando el tiempo de absorción de los nutrientes (García et al., 2008), podríamos inferir que esta especie tendría una capacidad de absorción de nutrientes intermedia.

En general la descripción microscópica de los órganos estudiados del tracto digestivo P. blochii se organizó de manera similar a la reportada para otros teleósteos, constituido por cuatro capas; mucosa, submucosa, muscular y serosa (Dai et al., 2007; Olaya et al., 2007; García et al., 2008; Gómez et al., 2010; Wilson y Castro 2011).

El esófago de P. blochii presentó una mucosa de epitelio plano estratificado con gran cantidad de células caliciformes las cuales han sido observadas en una amplia variedad de especies de peces (Muñoz et al., 2006; Dai et al., 2007; Olaya et al., 2007; Gómez et al., 2010; Wilson y Castro, 2011). Las células mucosecretoras también llamadas globosas o caliciformes son continuas y abundantes. El moco secretado por ellas facilita el paso de alimentos a lo largo del tracto digestivo, esto se observa en especies con diferentes hábitos alimenticios: en omnívoras como Leporinus friderici y Leporinus taeniofasciatus (Albrecht et al., 2001), también en carnívoras como Monopterus albus cuya secreción le permite la ingestión de pequeños animales acuáticos (peces y crustáceos) (Wilson y Castro 2011), y en Pimelodus maculatus, su número es mayor, pues esta especie ingiere escamas, fragmentos de espinas y restos que ratinizados de insectos, de no poseer esta adaptación lesionaria el epitelio de la mucosa, causando heridas y posibles infecciones (Santos et al., 2007).

La mucosa del estómago está compuesta por epitelio cilíndrico simple con presencia de abundantes glándulas gástricas encontradas en mayor proporción en la región cárdiaca y fúndica, similar a lo reportado en otras especies como P. maculatus (Santos et al., 2007), P. pictus (Olaya et al., 2007) y A. seemanni (Gómez et al., 2010). Las glándulas gástricas producen fluido gástrico que contiene enzimas digestivas similares a la de los mamíferos (Dai et al., 2007). La mayor actividad es realizada por enzimas proteolíticas, como se demostró en Pseudoplatystoma corruscans que al aumentar el contenido de proteína en la dieta este exhibía un incremento en la actividad proteolítica (Lundstedt et al., 2004). Otro producto de secreción de las glándulas gástricas es el ácido clorhídrico el cual ayuda a hidrolizar y desnaturalizar las proteínas en el estómago (Day et al., 2011).

La mucosa del intestino de $P$. blochii es un epitelio cilíndrico simple con células caliciformes, similar a lo encontrado en especies con diferentes hábitos alimenticios Salminus affinis, (García et al., 2008), Brycon siebenthalae (Eslava et al., 2001), lo contrario ocurre 
en el intestino de Gambusia punticulata y Girardinus metallicus, pues la mucosa presenta un epitelio de tipo cilíndrico pseudoestratificado (Rodríguez et al., 2004), aunque son capas mucosas diferentes cumplen funciones similares de absorción y secreción (Ross y Pawlina, 2011).

Hossain y Dutta (1996) estimaron que el $60 \%$ de las especies de peces conocidas poseen ciegos pilóricos los cuales varían en número, longitud y diámetro. $P$. blochii no presentó ciegos pilóricos lo que podría sugerir que en el intestino de la especie se produce mayor cantidad de enzimas proteasas las cuales le permiten degradar alimento con un alto contenido de proteína. Lo anterior también se puede evidenciar en especies del género Atherinopsis las cuales no poseen ciegos pilóricos y secretan principalmente proteasas, en la especie a gástrica y carnívora Atherinopsis affinis secreta mayor cantidad de tripsina y en Atherinopsis californiensis que es omnívora se secreta mayor cantidad de aminopeptidasa (Horn et al., 2006).

A diferencia de los mamíferos que presentan lobulaciones en el hígado P. blochii no presentó lobulaciones, como ocurre en la mayoría de teleósteos (Vicentini et al., 2005) Histológicamente el hígado de P. blochii es similar al de especies como: Huso huso, P. brachypomus, P. pictus (Sheibani y Pahlavan, 2006; Muñoz et al., 2006, Olaya et al., 2007) por lo cual se esperaría que cumpliera las mismas funciones de excreción (productos de desecho) y almacenamiento de lípidos (vitaminas A y B, glicógeno) entre otras (Wilson y Castro, 2011).

$P$. blochii presenta un páncreas difuso característico de la mayoría de los teleósteos (Vásquez-Torres, 2004), a diferencia de Huso huso que presenta un páncreas compacto y recubierto por una delgada capa de tejido conectivo, asociado al hígado lo que indica que pueden tener funciones conjuntas (Sheibani y Pahlavan, 2006). El páncreas en peces presenta dos tipos exocrino y endocrino; el tejido pancreático de tipo exocrino produce enzimas digestivas como proteasas (tripsina, quimotripsina, elastasa y lipasa), amilasa, quitinasas y lipasas; las cuales participan en los procesos de digestión cuando entran en contacto con el alimento en el lumen intestinal (Vásquez-Torres, 2004). Los ductos pancreáticos no son fácilmente distinguibles, pero se caracterizan por estar rodeados de tejido conectivo y poseer epitelio cúbico, estos ductos son los responsables de transportar las enzimas digestivas secretadas por las células acinares, estas enzimas son las responsables de la catálisis de proteínas, grasas, y carbohidratos (Vicentini et al., 2005; Wilson y Castro, 2011).

\section{Agradecimientos}

A la Vicerrectoría de investigaciones y a la Facultad de Ciencias de la Universidad Militar Nueva Granada. A Eduardo Jurado y a María Leonor Caldas.

\section{Referencias}

Agarwal NK. 1996. Fish Reproduction. APH Publishing Corporation Efficient offset printers, New Delhi, Indian.p.p. 120.

Albrecht MP, Ferreira MF, Caramaschi EP. Anatomical features and histology of the digestive tract oftwo related neotropical omnivorous fishes (Characiformes;Anostomidae). J Fish Biol, 2001; 58:419-430.

AVMA American Veterinary Medical Association. 2007. Guidelines on Euthanasia (Formerly Report of the AVMA Panel on Euthanasia), Jun:1-36.

Dai X, Shu M, Fang M. Histological and ultrastructural study of digestive tract of rice field eel Monopterusalbus. J Appl Ichthyol, $2007 ; 23: 177-183$

Day RD, German DP, Manjakasy JM, Farr I, Hansen MJ, Tibbetts IR. Enzymatic digestion in stomachlessfishes: how a simple gutaccommodates both herbivory and carnivory. J Comp Physiol, B,2011;181: 603-613.

Eslava PR, Cruz PE, Vasquez W, Iregui C. Morfología del Sistema digestivo de la Cachama Piaractus brachypomus. Revista de la Facultad de Medicina Veterinaria y Zootecnia. Unillanos, 2000; 2(2):22-31.

Eslava R, Suarez M, Pardo C, Arias C y Cruz C. Morfología macro y microscópica del esófago, estómago y ciegos pilóricos de yamú Brycon siebenthalae. Orinoquia, 2001; 5:111-128.

Gómez E, Tovar O, Obando MJ, Hurtado H. Estudio histológico del tracto digestivo del pez Ariopsis seemanni (Ariidae). Revista Facultad de Ciencias Básicas, 2010;6(2):216-225.

Hernández DR, Pérez M, Domitrovic HA. Morphology, Histology and Histochemistry of the Digestive System of South American Catfish (Rhamdia quelen). Int J Morphol, 2009; 27(1): 135-131.

Horn MH, Gawlicka AK, German D P. Structure and function of the stomachless digestive system in three related species of New World silverside fishes (Atherinopsidae) representing herbivory, omnivory and carnivory. Marine Biology, 2006;149: 1337-1345

Hossain AM, Dutta HM. 1996. Phylogeny, ontogeny, structure and function of digestive tract appendages (caeca) in teleost fish. En: Datta JS and Dutta HM, editors. Fish Morphology, Horizon of New Research. A.A Balkema/Rotterdam, Brookfield; p. 300.

López-CasasS, Jiménez SF. Reproduction and feeding of Nicuro, Pimelodus blochii (Valenciennes, 1840) (Pisces: Pimelodidae), in Cachimbero floodplain lake, Magdalena river basin, Colombia. Actualidades biologicas, 2007; 29 (87):193-201.

Lundstedt LM, Melo JFB, Moraes G. Digestive enzymes and metabolic profile of Pseudoplatystoma corruscans(Teleostei: Siluriformes) in response to diet composition. Comp Biochem Physiol, part B, 2004; (137):331-339. 
Maldonado-Ocampo JA, Ortega-Lara A, Usma OJS, Galvis VG, VillaNavarro FA, Vásquez GL, Prada-Pedreros S, Ardila RC. 2005 Peces de los Andes de Colombia. Instituto de Investigación de Recursos Biológicos «Alexander von Humboldt». Bogotá, D.C. - Colombia.

Lasso CA, Agudelo Córdoba E, Jiménez-Segura LF, Ramírez-Gil H, Morales-Betancourt M, Ajiaco-Martínez RE, de Paula Gutiérrez F, Usma Oviedo JS, Muñoz Torres SE, Sanabria Ochoa Al.(Editores). 2011. I. Catálogo de los recursos pesqueros continentales de Colombia. Serie Editorial Recursos Hidrobiológicos y Pesqueros Continentales de Colombia. Instituto de Investigación de Recursos Biológicos Alexander von Humboldt (IAvH). Bogotá, D. C., Colombia, p 715.

Muñoz A, Caldas ML, Hurtado H. Análisis histomorfológico del sistema digestivo y glándulas anexas en alevinos de Cachama blanca, Piaractus brachypomus (Characidae: Piaractus). Revista Facultad de Ciencias Básicas, 2006; 2:137-164.

Olaya CM, Ovalle CH, Gómez E, Rodríguez D, Caldas ML, Hurtado H. Histología y morfometría del sistema digestivo del silúridos Bagre Tigrito (Pimelodus pictus). Revista de la Facultad de Medicina Veterinaria y de Zootecnia, 2007; 54: 311-323.

Padilla PP, Alcántara BF, Ismiño OR. Reproducción inducida de la doncella Pseudoplatystoma fasciatum y desarrollo embrionariolarval. Folia Amazónica, 2001; 12(1-2): 141-155.

Rodríguez J, González E, Hernández N, Capó V, García I. Comparación morfológica e histológica del tubo digestivo de Gambusia punticulata y Girardinus metallicus, peces utilizados en el control biológico de mosquitos. Rev Cubana Med Trop, Instituto de Medicina Tropical Pedro Kourí. 2004; 56(1):73-76.

Ross MH, Pawlina W. 2011. Histology. A Text and Atlas with Correlated Cell and Molecular Biology. 6th ed. Lippincott Williams \& Wilkins, a Wolters Kluwer business. p 928.
Santos S, Duarte TG, Souza LT, Ribeiro AS, Araújo FG. Histologia e caracterização histoquímica do tubo gastrintestinal de $\mathrm{Pi}$ melodus maculatus (Pimelodidae, siluriformes) no reservatório de Funil, Rio de Janeiro, Brasil. Iheringia. Série zoologia, 2007; 97(4):413-417.

Seixas JT, Bras JM, Gomide AT, Oliveira MG, Donzele JL, Menin E. Anatomia funcional e morfometría dos intestinos e dos cecos pilóricos do teleostei (Pisces) de água doce Brycon orbignyanus (Valenciennes,1849). Rev Bras Zoot, 2000; 29(2):313-324.

Sheibani MT, Pahlavan Y.. Histological structures of the accessory glands of the digestive system in adult Caspian Sea beluga (Huso huso). J Applied Ichthyol, 2006; 22(1): 193-195.

Vásquez-Torres W. 2004. Principios de nutrición aplicada al cultivo de peces. $1^{\underline{a}}$ ed. Villavicencio, Colombia: Universidad de Los Llanos, p. 66.

Vicentini CA, Franceschini-Vicentini IB, Bombonato MTS, Bertolucci B, Lima SG, Santos AS. Morphological Study of the Liver in the Teleost Oreochromis niloticus. Inter J Morphol, 2005; 23 (3):211-216.

Villa- Navarro FA. 2010. 7.9 Siluriformes. Lasso CA,. Agudelo Córdoba E, Jiménez-Segura LF, Ramírez-Gil H, Morales-Betancourt M, Ajiaco-Martínez RE, de Paula Gutiérrez F,. Usma Oviedo JS, Muñoz Torres SE, Sanabria Ochoa Al. (Editores). 2011. I. Catálogo de los recursos pesqueros continentales de Colombia. Serie Editorial Recursos Hidrobiológicos y Pesqueros Continentales de Colombia. Instituto de Investigación de Recursos Biológicos Alexander von Humboldt (IAvH). Bogotá, D. C., Colombia. p. 461-463.

Wilson JM, Castro LFC. 2011. Morphological Diversity of the Gastrointestinal Tract in Fishes. En: Grossell M, Farrell PA, Brauner JC, editors. The Multifuctional gut of fish.1th ed. USA: Elseiver, p. 2-44. 